CESIS Electronic Working Paper Series

Paper No. 217

The Relationship between Exchange Rate and Interest Rate Differentials

- a Wavelet approach

R. Scott Hacker, Huynjoo Kim and Kristofer Månsson

Jönköping International Business School

February 2010 


\title{
The Relationship between Exchange Rates and Interest Rate Differentials: a Wavelet Approach
}

\author{
R. Scott Hacker, Hyunjoo Kim, and Kristofer Månsson \\ Department of Economics \\ Jönköping International Business School (JIBS) \\ P.O. Box 1026 SE-551 Jönköping, Sweden
}

\section{This Version}

November 26th, 2009

\begin{abstract}
This paper uses wavelet analysis to investigate the relationship between the spot exchange rate and the interest rate differential for seven pairs of countries, with a small country, Sweden, included in each of the cases. The key empirical results show that there tends to be a negative relationship between the spot exchange rate (domestic-currency price of foreign currency) and the nominal interest rate differential (approximately the domestic interest rate minus the foreign interest rate) at the shortest time scales, while a positive relationship is shown at the longest time scales. This indicates that among models of exchange rate determination using the asset approach, the sticky-price models are supported in the short-run while in the long-run the flexible-price models appear to better explain the sign of the relationship.
\end{abstract}

Key Words: exchange rates, interest rate differential, uncovered interest parity, monetary approach, small-economy, wavelet analysis

JEL Classification: E44, F31, F42 


\section{Introduction}

Different assumptions in the theoretical models of open-economy macroeconomics have previously led to dramatically different conclusions on various economic relationships, and often these differences have hinged on the assumed or derived relationship between the exchange rate between two countries and the interest rate differential between those countries. The legitimacy of the relevant assumptions has frequently been associated with the time scale we are considering - the long-run, in which product prices are perfectly flexible, or the short-run in which this is not the case. In this paper, wavelet decomposition is employed as an empirical methodology to help consider time-scale issues in studying the relationship between exchange rate and the interest rate differential. In so doing, this paper lends itself to an understanding of the time-varying relationship of the two given variables, an issue which has not been addressed thoroughly in previous empirical studies.

Asset-approach exchange rate determination models that assume product prices are perfectly flexible (as in the classical and neoclassical traditions) and bonds of different countries are perfectly substitutable, are referred to as flexible-price monetary models. ${ }^{1}$ In dealing with exchange rate determination, flexible-price monetary models rely heavily upon purchasing power parity in combination with some additional assumptions or theoretical results indicating a positive relationship between a country's nominal interest rate and its prices or inflation level (as in the Fisher (1930) hypothesis). As a result, these models tend to indicate there should be a positive relationship between the interest rate differential (defined as the "home" country's interest rate minus that of a "foreign" country) and the exchange rate (defined as the price of the foreign country's currency in terms of the home country's currency) or the change in that exchange rate.

In contrast, for determining short-run relationships involving the exchange rate, stickyprice models as in the Keynesian tradition rely heavily upon the exchange rate as an equilibrating variable to maintain either (i) a zero balance of payments in the face of incipient capital flows between countries arising from changes in interest rate differentials or (ii) the uncovered interest rate parity condition. As a result, these models tend to indicate there should be a negative relationship between the interest rate differential and the exchange rate. ${ }^{2}$

Previous papers have investigated the empirical performance of exchange-rate determination models of both traditions, an early one being that by Frankel (1979). This paper was followed by the seminal Meese and Rogoff (1983a) article, which indicated the difficulty of showing the forecasting superiority of fundamentals-based exchange rate determination models in comparison to a random walk, and by various other articles, especially in the last decade, likewise investigating forecast performance of these models. These papers often consist simply of time series regression results relating exchange rate movements to interest rate differentials and various other fundamental variables. However,

\footnotetext{
${ }^{1}$ Exchange rate determination models following an asset approach are those in which exchange rate movements are primarily equilibrating reactions to varying supplies and demands for various financial assets. The asset approach has following two implications: (1) the exchange rate concerns stocks of assets rather than flows of goods, and (2) a forward-looking behavior plays an important role in exchange rate determination. See Frenkel (1976).

${ }^{2}$ More recent exchange rate determination models within the "new open economy macroeconomics" tradition, e.g. Obstfeld and Rogoff (1995) and Betts and Devereux (2000) allow for sticky prices but vary in their indications of how the interest rate differential is related to the exchange rate. These models will be discussed in the following section.
} 
they typically do not deal empirically with allowing the coexistence of short-run relationships (with sticky prices) and long-run relationships (with flexible prices) between the same two variables. In discussing the relationship between the interest rate differential and the exchange rate, the time scale considered is clearly important.

Due to the importance of time scale in this issue, a time series methodology that is able to consider the movements of the examined variables at various scales is clearly desirable. Wavelet decomposition provides a multi-scale analysis and bears a resemblance to the activity of a camera-lens. Zooming out the lens brings a broad landscape, while zooming in the lens allows you to find details which were not observable in the landscape portrait. In mathematical terms, "wavelets are local orthonormal bases consisting of small waves ${ }^{3}$ that dissect a function into layers of different scale" (Schleicher, 2002, p.1). This dissection of time series into different layers makes wavelet analysis a very useful tool in economics because most economic time series consist of different layers due to economic agents making decisions with different time horizons. For instance, in the currency market there are intraday traders, day traders, and long-term traders. It is the aggregation of the activities of all traders with different time horizons that generates the exchange rate. By using wavelet analysis one can decompose the time-series (i.e. the spot exchange rate) into the different layers and thus zoom in on the activity of the traders at different time scales. We are also able to zoom out and obtain the broad landscapes which correspond to longer-term trends of the time series.

This paper uses wavelet decomposition to investigate the relationship between the exchange rate and the interest rate differential over different time scales and to determine whether some types of economic models explain the relationship better in some time horizons than in others. In contrast to many previous studies which have focused on bilateral relationships in exchange rates and interest-rate differentials between the US and other large developed economies, this paper focuses on such bilateral relationships between a 'small country', Sweden, and various other national economies. By 'small country', what is meant that developments in that country do not induce any perceptible effect on the rest of the world, thereby justifying in economic modeling the treatment of foreign variables as being given. This focus is useful since many open macroeconomic models take advantage of such a "small country" assumption.

This paper is structured as follows. Sections 2 and 3 provide theoretical and empirical backgrounds on the relationship between interest rate differentials and the exchange rate. Section 4 motivates the new approach, wavelet analysis, in investigating the relationship on a scale-by-scale basis. Section 5 describes the data and testing methodology used in this paper. Empirical results are presented in section 6. In section 7, our main findings are summarized.

\section{Background on the economic theory}

In the introduction it was noted that exchange rate determination models in the flexibleprice monetary tradition tend to indicate there should be a positive relationship between the interest rate differential and the exchange rate or the change in that exchange rate. Here we explain two ways by which this positive relationship can come about. First, an exogenous increase in the home country's interest rate (not due to money supply reduction), all else equal will drive down money demand in that country and drive up its aggregate demand, resulting in higher prices in that country, ${ }^{4}$ and through relative purchasing power parity the

\footnotetext{
${ }^{3}$ A wavelet means a 'small wave' compared to, for example, the sine function which can be considered as a 'big wave'. A real-valued function, $\varphi(-)$, defined over the real axis $(-\omega, \omega)$ leads to 'small waves' with the two basic properties: (1) the integral (sums) of $\varphi(-)$ is zero; (2) the square of $\varphi(-)$ integrates (sums) to unity. In case of the sine function, the second property is not satisfied, thus it is not a 'small wave', but a 'big wave'.

${ }^{4}$ Suppose that money demand is of the Cambridge form $M^{d}=k P Y$, where $M^{d}$ is money demand, $P$ is the aggregate price level, $Y$ is real national income, and $k$ is a variable which is a negative function of the interest
} 
exchange rate will rise (the home country's currency depreciates against the foreign country's currency). "Relative purchasing power parity" refers to having a constant real exchange rate, i.e. $E P^{*} / P$, where $E$ is the exchange rate (the price of foreign currency in terms of domestic currency), $P^{*}$ is the foreign price level, and $P$ is the home country's price level. Relative purchasing power parity is equivalently defined as having the rate of change in the exchange rate equal to the home country's price inflation minus the foreign country's price inflation.

Second, assuming perfect foresight (so expected inflation and actual inflation are equivalent) an increase in the inflation in the home country all else equal tends to lead to both (1) a rise in the exchange rate due to relative purchasing power parity and (2) a rise in the nominal interest rate via the Fisher (1930) hypothesis, which asserts that any increases in expected inflation of country should, all else equal, be matched by an increase in that country's nominal interest rate.

The introduction also indicated that some sticky-price models rely on the exchange rate to maintain a zero balance of payments in the face of incipient capital flows induced by interestrate differential changes, and that a negative relationship between the interest rate differential and the exchange rate results. The most celebrated version of this type of modeling was by provided by Robert Mundell $(1962,1963)$ and J. Marcus Flemming (1962), who extended the Keynesian income-expenditure model to include capital inflows into the IS-LM model of the aggregate demand. Given the assumption of sticky-prices in the short-run, a relatively lower home-country interest rate due to a monetary expansion in the home country results in capital outflow from the home country, inducing an incipient balance of payments deficit which is resolved by increasing net exports through a rise in the spot exchange rate (i.e. depreciation of the domestic currency). This negative relationship between interest rate differential and exchange rate also applies with other policy measure, fiscal expansion. ${ }^{5}$

The model developed by Mundell and Fleming lacked an explicit treatment of expectations of exchange rate changes, and did not show what happens to the economy in transition from the sticky-price short-run situation to the flexible-price long-run equilibrium. These problems were resolved in the model originally formulated by Rudiger Dornbusch (1976), which is a hybrid of the two extreme opposite modeling worlds in exchange rate determination: modeling with perfectly-flexible prices and modeling with fixed prices as in the initial Mundell-Fleming framework. This model, often referred to as the Dornbusch overshooting model, includes price-stickiness in product markets as a short-run feature and price adjustment in the long-run, at which point it displays the characteristics of the flexibleprice monetary model. This model is also sometimes referred to as a sticky-price monetary model, since it still focuses on monetary factors in determining exchange rate movements with product prices that are initially inflexible. ${ }^{6}$

The Dornbusch overshooting model relies upon the uncovered interest rate parity condition:

rate (a higher interest rate increases the opportunity cost of holding money). Setting money supply equal to money demand and solving for $P$ we get $P=M^{S} /(k Y)$, which acts as an aggregate demand function. An increase in the interest rate, all else equal, causes $k$ to drop and $P$ to rise.

${ }^{5}$ The negative relationship between interest rate differential and exchange rate, however, applies only to the high capital mobility scenario. The lower capital mobility scenarios are not considered in this paper given that the financial markets in this study are quite frictionless.

${ }^{6}$ Monetary models of exchange rate determination, of which there are both flexible price and sticky price forms, focus on the monetary factors affecting the exchange rate. They are based on the definition of exchange rate as a relative price of two currencies and the relative price is modeled in terms of the relative supply and demand for the two currencies. Neutrality of money (in the long run) characterizes this these models. (Sarno and Taylor, 2002) 


$$
R=R^{*}+\frac{E^{e}-E}{E},
$$

where $R$ and $R^{*}$ are respectively the home and foreign country's nominal interest rates, $E$ is the spot exchange rate (price of foreign currency in terms of domestic currency), and $E^{e}$ is the expectation of the exchange rate in the future. Inclusion of the expected rate of depreciation $\left(E^{e}-E\right) / E$ makes the interest rates comparable in the same currency. ${ }^{7}$ If uncovered interest rate parity did not hold then arguably capital flows would induce it to be so, as investors move their investments toward the country with the highest expected return, and thereby driving up the price of that country's currency. Equation (1) may be rewritten as

$$
R-R^{*}=\frac{E^{e}}{E}-1
$$

which shows the basis of the short-run negative relationship between the interest rate differential and the exchange rate found in many sticky-price models. A permanent homecountry monetary expansion in this model is accompanied in the short-run by an decrease in $R$ and a rise in $E^{e}$ (due to the upward pressure on the home country's long-run prices leading to expectations of a depreciated currency in the future through relative purchasing power parity) and a rise in $E$ that is greater than the increase in $E^{e}$ to make sure equation (2) stays in equilibrium given $R^{*}$ as fixed. ${ }^{8}$ Between the short-run and the long-run, prices rise, decreasing the real money supply and increasing $R$, which must be accompanied by $E$ declining to maintain equation (2). Thus what we see out of this model is a negative relationship between $R-R^{*}$ and $E$ concurrently, although without contradiction there is also a tendency for periods with lower $R-R^{*}$ to be associated with $E$ increasing less quickly assuming rational expectations. The former negative relationship is an immediate short-term one, and the latter positive relationship may be conceived as a longer-term one that requires changing prices. However, in the true long run for the Dornbusch model, monetary shocks have $n o$ effect on the interest rate differential so they cannot induce any long-run relationship between the interest rate differential and the exchange rate at that time scale.

Compared to the flexible-price and sticky price monetary models, the portfolio balance approach relaxes the assumption that domestic and foreign bonds are prefect substitutes. Agents, in this approach, allocate their wealth among different assets-domestic money, domestic bonds and foreign bonds for example. Exchange rates play a role of balancing asset demand and supplies, although the possible existence of a nonzero risk premium prevents the uncovered interest rate parity from holding. In portfolio balance models (see Branson and Henderson (1985) provides for earlier foundations of the approach), ${ }^{9}$ the assertion that the demand for foreign denominated assets is negatively related to $R$ and positively related to $R^{*}$

\footnotetext{
${ }^{7}$ Formally the uncovered interest rate parity condition in equation (1) is just an approximation, but it is often used in theoretical works. The exact version of uncovered interest rate parity is $R=\left(E^{e} / E\right)\left(1+R^{*}\right)-1$ or equivalently $1+R=\left(E^{e} / E\right)\left(1+R^{*}\right)$. Dornbusch (1976) used the version $R-R^{*}=\theta\left(\ln E_{L R}-\ln E\right)$, where $E_{L R}$ is the long-run level of $E$, and $\theta$ is a constant so $\theta\left(\ln E_{L R}-\ln E\right)$ can be interpreted as approximately the expected rate of depreciation, constrained such that it increases the further the exchange rate is from its long-run equilibrium level.

${ }^{8}$ In the case of monetary acceleration, on the contrary, a positive relationship between the two variables through the Fisher effect can be explained. This positive relationship supports the explanation of the flexible-price model mentioned in an earlier section, which explains the long-run relationship between the two variables.

${ }^{9}$ Most recent works on portfolio models of the current account in a general equilibrium context for open economies include Blanchard, Giavazzi, and Sa (2005) and Edwards (2005). See Copeland (2008) for a simple textbook presentation of this approach.
} 
$+\left(E^{e}-E\right) / E$ allows for an implicit negative relationship between $E$ and $R-R^{*}$ when setting the supply of foreign bonds equal to the demand for foreign bonds, which again results in the negative relationship between $E$ and $R-R^{*}$ in reaction to changes in the domestic money market.

The Redux model of Obstfeld and Rogoff (1995), which is a general equilibrium exchange-rate determination model dealing with two countries, monopolistically competitive industries, sticky prices, and an intertemporal approach to the current account balance, assumes uncovered interest rate parity but monetary shocks simply cause nominal interest rates to change by the same amount in both countries so no expected depreciation or appreciation after that change is created. However, within the appendix of Obstfeld and Rogoff (1995) paper, an alternative small open economy model with nontraded consumption goods is presented, and that model does have the possibility of exchange-rate overshooting in reaction to a money-supply increase. Lane (2001) notes that that overshooting is associated with a lowered short-run nominal interest rate. Betts and Devereux (2000) adjusted the Redux model by including pricing to market through local currency pricing, and found that under such circumstances a monetary expansion could lead to the interest rate differential decreasing along with exchange rate overshooting ( a static version of this model was provided in Betts and Devereux, 1996).

\section{Previous empirical work}

The efforts to tie the floating exchange rate to macroeconomic fundamentals such as relative money supply, output, and interest rates has long been studied in international macroeconomics. The monetary approach follows the models of Frenkel (1976), Bilson (1978), Dornbusch (1976) and Frankel (1979), which are based on the log-linear money market relationship (home money supply is a function of log of output and the home interest rate), purchasing power parity and uncovered interest rate parity. The validity of various theoretical models of exchange rate determination was investigated by Frankel (1979), who followed the tradition of Dornbusch (1976). Frankel's empirical equation is represented as the following:

$$
e=c+\gamma\left(m-m^{*}\right)+\delta\left(y-y^{*}\right)+\alpha\left(r-r^{*}\right)+\beta\left(\pi-\pi^{*}\right)+u,
$$

where $e, m$, and $y$ are respectively logs of the spot exchange rate, domestic money supply and output; $\pi$ is the current rate of expected long-run inflation at home (for which a proxy variable is used); $r$ is the log of one plus the domestic rate of interest; variables with asterisks correspond to foreign variables; $c$ is a constant; and $u$ is an error term. As was discussed earlier, sticky-price models as in the Keynesian tradition explain that there should be a negative relationship between the exchange rate and the interest rate differential, which leads to the hypothesis that $\alpha<0$ in the empirical equation. On the other hand, flexible price monetary models suggest that the relationship between those variables should be positively related, thereby leading to the hypothesis that $\alpha>0$ (Bilson, 1978), at least if the inflation differential is excluded. ${ }^{10}$ The theoretical development in the modeling of Frankel (1979) was to include both the nominal interest rate differential and the inflation differential in the model so that the former can capture the short-run effect on the exchange rate while the latter can

\footnotetext{
${ }^{10}$ The inclusion of the inflation differential can lead to some models within the flexible-price monetary tradition to suggest that instead $\alpha=0$ and $\beta>0$ due to the assumption of real interest rate parity or due to the assumption that real money demand is a negative function of inflation rather than of the nominal interest rate (Frenkel, 1976).
} 
explain the long-run effect when the prices are flexible. Frankel's theoretical model (known as the real interest differential model) concurs with the Dornbusch (1976) model in concluding that $\alpha<0$, but in contrast with the Dornbusch model which asserts that $\beta=0$, Frankel's model results in $\beta>0 .{ }^{11}$ Using monthly data from the mid-1970s between the Deutschmark and the US dollar along with the relevant other explanatory variables from Germany and the United States, Frankel found empirical support for his model.

The monetary approach to model exchange rate movements (both the flexible-price and sticky-price versions) has remained as a dominant paradigm since the 1970s and has stimulated different empirical studies on the exchange rate determination. Hooper and Morton (1982) extended the real interest rate differential model by including accumulated movements in the current account and a time trend as determinants of the real exchange rate in the long run. ${ }^{12}$ Theoretical developments in the empirical modeling of the exchange rates have included the incorporation of the presence of non-traded goods so that real exchange rate is arguably a function of the differential productivity growth of tradable and non-tradable sectors (Balassa, 1964; Samuelson, 1964; Obsfeld, 1993; and Asea and Mendoza, 1994). The empirical studies in the Balassa-Samuelson vein, where productivity differentials help explain exchange rates movements, have provided results that indicate the equilibrium exchange rate is influenced both by real shocks such as productivity innovations and by monetary shocks which influence the relative demands and supplies of monies. (Clements and Frenkel, 1980; DeGregorio and Wolf, 1994; and Chin, 1997). The general representation of the models in this tradition replaces the inflation differential variable with a productivity differential variable.

However, there have been empirical puzzles and failures of the monetary models which pose general challenges to modeling the exchange rate. Meese and Rogoff's (1983a, 1983b) finding that monetary models do not outperform a random-walk model has been a conclusion difficult to overturn (Mark and Sul, 2001; Rapach and Wohar, 2002; Faust, Rogers and Wright, 2003; Cheung, Chinn, and Pascual, 2005) ${ }^{13}$. The extensive analysis on the forecasting performance of different models and specifications has failed to point to any given model as being very successful. Since Meese and Rogoff (1983a, 1983b), most of the empirical works investigating the predictability of the monetary models have suffered from a number of econometric problems: especially endogeneity of the explanatory variables and persistence of the variables in the regression (Neely and Sarno, 2002). The endogeneity problem regards the fact that the typically included explanatory variables such as the relative money supply and the relative income and interest differential, i.e. fundamental variables, are determined within the economic system. Instrumental variables have been used in previous studies to deal with the endogeneity problems, however, finding legitimate instrumental

\footnotetext{
${ }^{11}$ The models in the sticky-price and flexible price monetary traditions typically do not conflict on what the anticipated estimates for $c, \gamma$, and $\delta$ should be (the estimate for $c$ should be approximately zero ideally for no risk premium, the estimate for $\gamma$ should approximately be equal to one to take into account long-run reactions to money supply variations, and $\gamma$ should be negative as an income increase is associated with an increase in money demand which has the opposite effect of an increase in money supply).

12 In Hooper and Morton (1982), $\quad x-r^{2}+\beta\left(\pi-\pi^{2}\right)$ in equation (1) was changed to

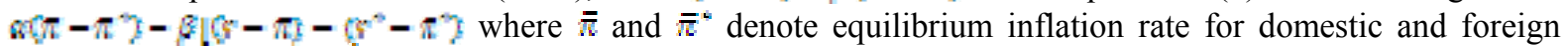
countries, respectively. They estimated empirically that $a>0$ and $\beta>0$.

${ }_{13}$ Mark (1995) and Chinn and Meese (1995), however, have shown predictability of exchange rates at long horizons although their works were criticized by other researchers, for example, Berkowits and Giorgianni (2001) showed that Mark's assumption on cointegration of the economic variables do not hold.
} 
variables which are highly correlated to the explanatory variables while orthogonal to the error term has been difficult (Meese and Rogoff, 1983b).

Chinn and Meridith $(2004,2005)$ presented empirical estimates of how the change in the log exchange rate is linearly related to the interest rate differential using short-maturity bond data, and more innovatively, long-maturity bond data. They found that a positive relationship between these variables (consistent with uncovered interest parity along with rational expectations) was observable when using long-maturity data but the opposite occurred when using short-maturity data. Their estimated positive relationship using long-maturity bond data is consistent with similar findings by Flood and Taylor (1996) using medium-maturity bond data, whereas their estimated negative relationship using short-maturity bond data is a common finding (see the findings in Froot and Thaler , 1990, on a survey of published estimates on this issue).

\section{Wavelet analysis}

Given that the extensive literature on the empirical estimations for explaining behaviors of the exchange rates still suffers from the weaknesses as discussed above, this paper tries to deal empirically with the coexistence of short-run relationships (with sticky prices) and longrun relationships (with flexible prices) between the exchange rate and the interest rate differential. The time scale is clearly very important in discussing these relationships, so our tool for handling this, wavelet analysis, is briefly described in this section.

In this paper we perform an additive decomposition on each of our time series through wavelets based on filtering using the Haar (1910) function, ${ }^{14}$ which has the shape shown in Figure 1.

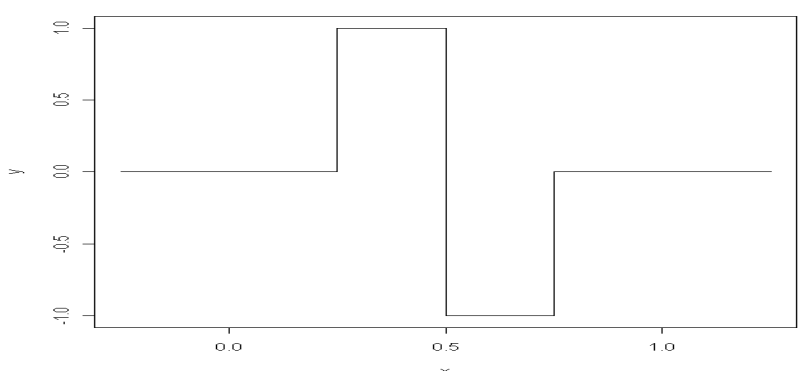

Figure 1. The Haar Wavelet

More specifically, the Haar function, $\psi(\lambda, k, x)$ is defined such that it takes on values of $0,-1$, or 1 , with the interval over $x$ for which $\psi$ is 1 or -1 being larger as the scale level $\lambda$ gets larger and with that interval being shifted rightward as the shift parameter $k$ increases. ${ }^{15}$ A scale level of $\lambda$, which is a positive integer, indicates we are dealing with patterns in the original data set associated with movements which occur with a frequency of every $2^{\lambda-1}$ periods (e.g. $\lambda$ $=1$ is associated with changes which occur after one period, $\lambda=2$ is associated with changes which occur after two periods, and $\lambda=4$ is associated with changes which occur after eight periods). A linear combination of many forms of this function, appropriately shifted through $k$ and expanded through increasing $\lambda$ (and squeezed by reducing $\lambda$ ) along with the overall

\footnotetext{
${ }^{14}$ The Haar function is used for the filtering since the difference between the properties of different wavelet filters is very small when using multiresolution analysis (Percival and Walden, 2006), which we discuss later. Additionally, the Haar filter is better at decorrelating time series (Percival, Sardy, and Davison, 2000).

15 The Haar function is more specifically given by $\Psi\left(n 2^{-\lambda} x-k\right)=\left\{1\right.$ if $n 2^{-\lambda} x-k \in[0,0.5)$; - 1 if $n 2^{-\lambda} x-k \in[0.5,1)$; otherwise \}, where $n$ the base-2 log of the number of elements in the original series rounded to an integer. In other presentations of the Haar function, $n 2^{-\lambda}$ is replaced by $2^{j}$, with $j$ representing a dilation parameter, which reduces the scale level as it increases.
} 
mean of the time series allows a perfect reproduction of the data. For example, suppose that $y$ is a vector of data and $n$ is the base- $2 \log$ of the number of elements in that vector rounded up to the nearest integer. ${ }^{16}$ That vector may be represented by the output from $f(x)$ for $x$ in the domain $[0,1]$ in the following wavelet transformation:

$$
f(x)=c_{0}+\sum_{\lambda=1}^{n} \sum_{k=0}^{n 2^{-\lambda}-1} c_{\lambda k} \psi(\lambda, k, x),
$$

where $c_{0}$ is the overall mean of the data and it along with the $c_{\lambda k}$ values are the wavelet coefficients. ${ }^{17}$ The fact that we are performing an additive decomposition, in contrast to a integrable decomposition, leads to this type of wavelet decomposition being referred to as discrete rather than continuous.

A quick way to calculate the wavelet coefficients is through a methodology introduced by Mallat (1989) referred to as multiresolution analysis (MRA), which also conveniently provides a rather intuitive interpretation of the wavelet decomposition. Briefly, it is simply a matter of finding averages (means, perhaps weighted) and differences from those averages, starting with values in the series closest to each other-the lowest scale-and repeating that process with the previous average series, gradually expanding how much of the original data is included in each successive average, i.e. increasing the scale.

If in each step each value in the series on which averages are being taken is used once and only once in computing those averages, and (assuming the use of the Haar function) the averages are simply between pairs of contiguous values, then with some standard normalization this results in a (non-overlapping) discrete wavelet decomposition (DWT). Under DWT, the wavelet transformation is an orthogonal one, and its MRA has no redundancy, providing just enough information-from the averages at one scale along with differences from averages at that scale and lower scales-to reconstruct the original series. When using DWT, at each successively higher scale level there are half the number of averages than at the previous scale level, which reduces the amount of observable variation in the averages series associated with higher scale levels. DWT is also sensitive to where one starts in pairing numbers for averaging.

Some of the undesirable properties from the DWT arise from the fact that it does not use moving averages. The methodology referred to as maximum overlap discrete wavelet decomposition (MODWT), which is the methodology used in this paper, does allow for moving averages at every scale level and avoids the problems of calculating the moving averages consistently throughout the series by reusing observations in a circular loop, i.e. what is considered the next value after the last value of the original series is simply the first value of that series. Unlike DWT, MODWT has the number of values for the averages at every scale level equal to the number of values in the original series, which is a useful property for our analysis. The wavelet transformation for MODWT is not an orthogonal one, however.

\footnotetext{
${ }^{16}$ In a discrete wavelet transformation, the number of elements must exactly be equal to $2^{n}$ for some integer $n$, so no rounding would be involved.

${ }^{17}$ Grossman and Morlet (1984) are credited with being the first to formally define a wavelet in dealing with quantum physics. Orthonomal bases in some variation of the form noted in equation (4) was provided first by Strömberg (2006).
} 
At every scale level $\lambda$, the MRA for MODWT produces (1) a series of the averages at that scale, referred to as that level's smooth series, $s_{\lambda}$, in which the averages are over values in the next-lower scale level's smooth series, and (2) a series of the differences of the smooth series at the next-lower level from the current-level's smooth series, referred to as the detail series, $d_{\lambda}$, for scale level $\lambda$. The zero-level smooth series is the original data series, since at the zerolevel there is no smoothing of the data.

To understand how the calculations for the smooth and detail series for the MRA of the MODWT are performed with the Haar function, consider the following. Suppose we have a vector of actual time series observations $y$, with its elements ordered according to uniform units of time, as are the vectors with the level- $\lambda$ smooth and detail series, $s_{\lambda}$ and $d_{\lambda}$. Element $t$ (representing time) of $y, s_{\lambda}$ and $d_{\lambda}$ are respectively given by $y_{t}, s_{\lambda, t}$, and $d_{\lambda, t}$. Let the level-zero smooth series $s_{0}$ be defined to be the same as the vector of actual observations $y$. The following two formulas describe how the smooth and detail series are calculated at scale levels of 1 and higher:

$$
\begin{aligned}
& s_{\lambda, t}=\frac{s_{\lambda-1, t 2^{\lambda-1}}+2 s_{\lambda-1, t}+s_{\lambda-1, t+2^{\lambda-1}}}{4} \\
& d_{\lambda, t}=\frac{-s_{\lambda-1, t 2^{\lambda-1}}+2 s_{\lambda-1, t}-s_{\lambda-1, t+2^{\lambda-1}}}{4}
\end{aligned}
$$

Below we demonstrate the pattern on how these equations work for three scale levels. Keeping in mind that $s_{0, t}=y_{t}$, at scale level 1 we have

$s_{1, t}=\left(y_{t-1}+2 y_{t}+y_{t+1}\right) / 4$ and $d_{1, \mathrm{t}}=\left(-y_{t-1}+2 y_{t}-y_{t+1}\right) / 4$.

At scale level 2 we have

$s_{2, t}=\left(s_{1, \mathrm{t}-2}+2 s_{1, \mathrm{t}}+s_{1, t+2}\right) / 4$ and $d_{2, \mathrm{t}}=\left(-s_{1, \mathrm{t}-2}+2 s_{1, t}-s_{1, t+2}\right) / 4$,

at scale level 3 we have

$s_{3, t}=\left(s_{2, t-4}+2 s_{2, \mathrm{t}}+s_{2, \mathrm{t}+4}\right) / 4$ and $d_{3, t}=\left(-s_{2, t-4}+2 s_{2, t}-s_{2, t+4}\right) / 4$.

and at scale level 4 we have

$s_{4, t}=\left(s_{3, t-8}+2 s_{3, t}+s_{3, t+8}\right) / 4$ and $d_{4, t}=\left(-s_{3, t-8}+2 s_{3, t}-s_{3, t+8}\right) / 4$.

It is always the case that the original series may be reconstructed from adding to the smooth series of the largest scale level considered, Л, the sum of the detail series from level 1 to level Л, i.e.

$$
y=s_{\Lambda}+\sum_{\lambda=1}^{\Lambda} d_{\lambda} .
$$

If we return to the introduction's example of the spot exchange rate, with its observations included in the vector $y$, then $y_{\mathrm{t}}$ reflects an aggregation at time $t$ of activities for the traders with different time horizons. The associated wavelet details, $d_{1}$ to $d_{Л}$ are the decompositions of the spot exchange rate at different time scales. Finally $s_{\text {Л }}$ represents the long-term trend of 
the spot exchange rate at scale-level Л, which corresponds to zooming out the camera lens and looking at the broad landscape.

\section{Data description and testing methodology}

Among the data used in this study are monthly and quarterly spot exchange rates against the Swedish krona (SEK) of five major currencies (the U.S. dollar, USD; the Japanese yen, JPY; the euro, EUR; the Pound sterling, GBP; and the Swiss franc, CHF) and two other currencies (the Norwegian krone, NOK; and the (South) Korean won, KRW). These data were collected from the foreign exchange (FX) history database provided by the OANDA corporation and are averages of ask prices. Interest rates data were also collected and are based on the yields from the three-month T-bill since its return is simply the three-month interest rate. The data on the interest rates are from Ecowin database, which gathered the data from Reuters and central banks (Federal Reserve, The Bank of England, and the Bank of Korea). Both spot exchange rates and interest rates are end-of-the month observations. The starting month of the sample period varies for each currency depending on the availability of data in the floating period of the exchange rate. For the Swedish krona the sample period starts from January, 1993; for the Korean won January, 1998; for the euro January, 2000; and for the Swiss franc May, 2000. The sampled periods are covered up to May, 2009.

The spot exchange rate is in logarithmic form (denoted as $\ln E$ in the regression and in figures with upper case $E$ denoting the spot exchange rate) and the nominal interest rate differential (denoted as Rdiff in the regression and figures) is defined as the difference between the $\log$ of one plus the Swedish rate of interest and the $\log$ of one plus the foreign rate of interest. ${ }^{18}$ Throughout the rest of this paper, Rdiff will be simply referred to as the interest rate differential even though formally it is not exactly the same as $R-R^{*}$, as noted above.

In Figures 2 and 3 the raw data and the wavelet filtered data of the spot exchange rate and the interest rate differential between Sweden and US are shown, broken out into six different scale levels. ${ }^{19}$ In our empirical presentation here and later, we follow the convention of our software, and have the level of a smooth or detail appended to $s$ or $d$ not subscripted and removed the italics on $s$ and $d$, e.g. $\mathrm{s} 1 \equiv s_{1}$ and $\mathrm{d} 2 \equiv d_{2}$. Due to the construction of the scale levels, $\mathrm{d} 1$ is associated with a one-period movement frequency (changes can occur between consecutive periods), $\mathrm{d} 2$ with a two-period movement frequency (changes occurring every two periods), d3 with a four-period movement frequency, d4 with an eight-period movement frequency, d5 with sixteen-period movement frequency, and d6 with a thirty-two period movement frequency. The wavelet scale refers to these movement frequencies. The nonstationary components (trend) of the time series will be found in the wavelet smooth, s6. For each variable, the variation of the detail series at each time scale tend to differ. Time series plots of the wavelet filtered data in Figures 2 and 3 show that at the longer time scales the oscillations of the time series are longer; as the time scale increases the time between consecutive peaks and between consecutive troughs gets longer. The wavelet smooth representing the trend (s6) illustrates that the peak of the exchange rate was around the year 2002, which is also noticeable from the original time series of the exchange rate.

\footnotetext{
${ }^{18}$ As noted in footnote 7 , an exact version of the uncovered interest rate parity conditions is given by the equation $1+R=\left(E^{e} / E\right)\left(1+R^{*}\right)$. Taking logs on both sides and rearranging we get $\ln E=\ln E^{e}-\left(\ln (1+R)-\ln \left(1+R^{*}\right)\right)$, which gives the reason behind why we define Rdiff the we way we do.

19 Since it would take too much space to present all time series only one is presented. Graphs over all wavelet filtered time series are, however, available from the authors upon request.
} 

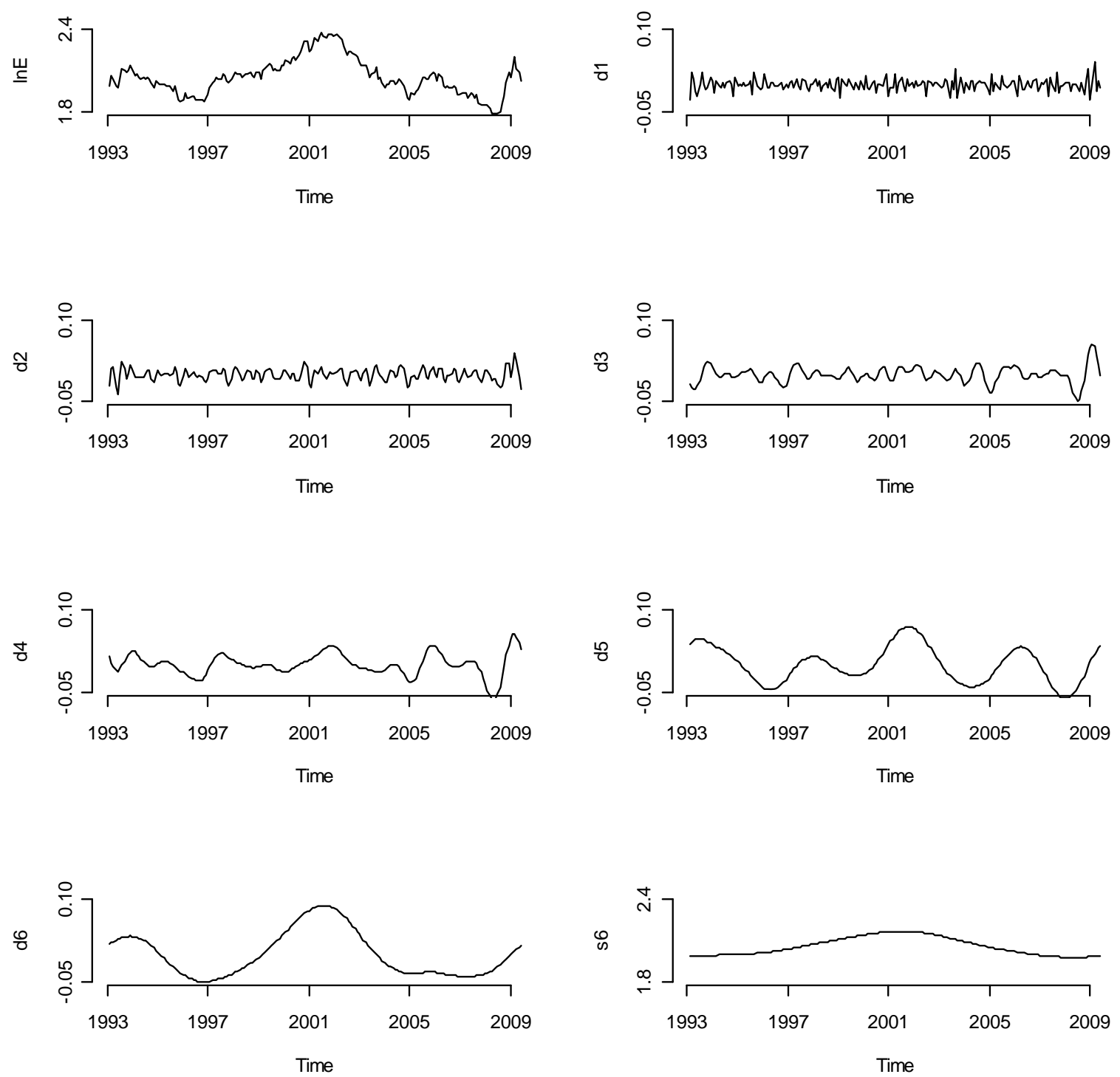

Figure 2. Time series plots of data for the monthly spot exchange rate (SEK/USD in log scale)

To investigate the impact on the interest rate differential on the exchange rate at a particular scale, a simple regression as below was estimated by ordinary least squares using the wavelet detail series at the same level for $\ln E$ and Rdiff in order to investigate the sign of the $\beta$ parameter:

$$
\ln E\left[d_{\lambda}\right]_{t}=\alpha_{\lambda}+\beta R \operatorname{diff}\left[d_{\lambda}\right]_{t}+\varepsilon_{\lambda, t}
$$

where $\ln E\left[d_{\lambda}\right]_{t}$ and $R \operatorname{diff}\left[d_{\lambda}\right]_{t}$ represent the time- $t$ elements of the scale-level $\lambda$ detail series for $\ln E$ and Rdiff respectively. The advantage of this method is that it is very simple and one can by this method easily see if the interest rate differential has a positive or negative effect on the exchange rate. Nonetheless, this simple method is not devoid of problems. First, due to the reuse of observations in a circular loop (as explained in section 4), observations at the endpoints of the detail series at the lower scales often have outliers. As an example of the source of these outliers, one can see in the d1 series in Figure 2, that there are exceptionally 
high values that occur at the endpoints, which arise from the large difference in where the raw data series starts and where it ends. To deal with this problem, the detail series were in some cases truncated from the left and/or right to remove outliers prior to running the regressions. Second, the misspecification tests (the Breusch-Godfrey LM-test for GARCH effects and autocorrelation) indicate that there is a problem with autocorrelation and GARCH effects in most of the cases. As a remedy to this problem robust standard errors (NeweyWest) are used. ${ }^{20}$ Third, for explaining exchange rate movements there are additional theoretically-justified "fundamental" variables, such as relative money supply and relative income in monetary models, the relative expected inflation differential in the real interest rate differential model of Frankel (1979), and the current account, as in the Hooper and Morton (1982) model. Regarding this problem of potential omitted variable bias, we pose that other fundamental variables which affect the dependent variable, $\ln E$, are in many cases irrelevant at a particular scale to the extent that they only affect $\ln E$ at a different (often lower) frequency than the one being examined.

\footnotetext{
${ }^{20}$ Autocorrelations were detected in the residuals from the regression particularly at larger scales (d4, d5). To correct the autocorrelation problem, we used the Marquardt nonlinear least squares algorithm which estimate both the slope estimates and the coefficient of autocovariance (see details in Davidson and MacKinnon, 1996). The lag-lengths of the AR models were decided based on the Akaike Information Criteria (AIC). Regressions with this model showed different results at the scales of $\mathrm{d} 4$ and $\mathrm{d} 5$ where no significant positive $\beta$ estimates were found. However, we could check the robustness in the finer frequencies (d1 to d3).
} 

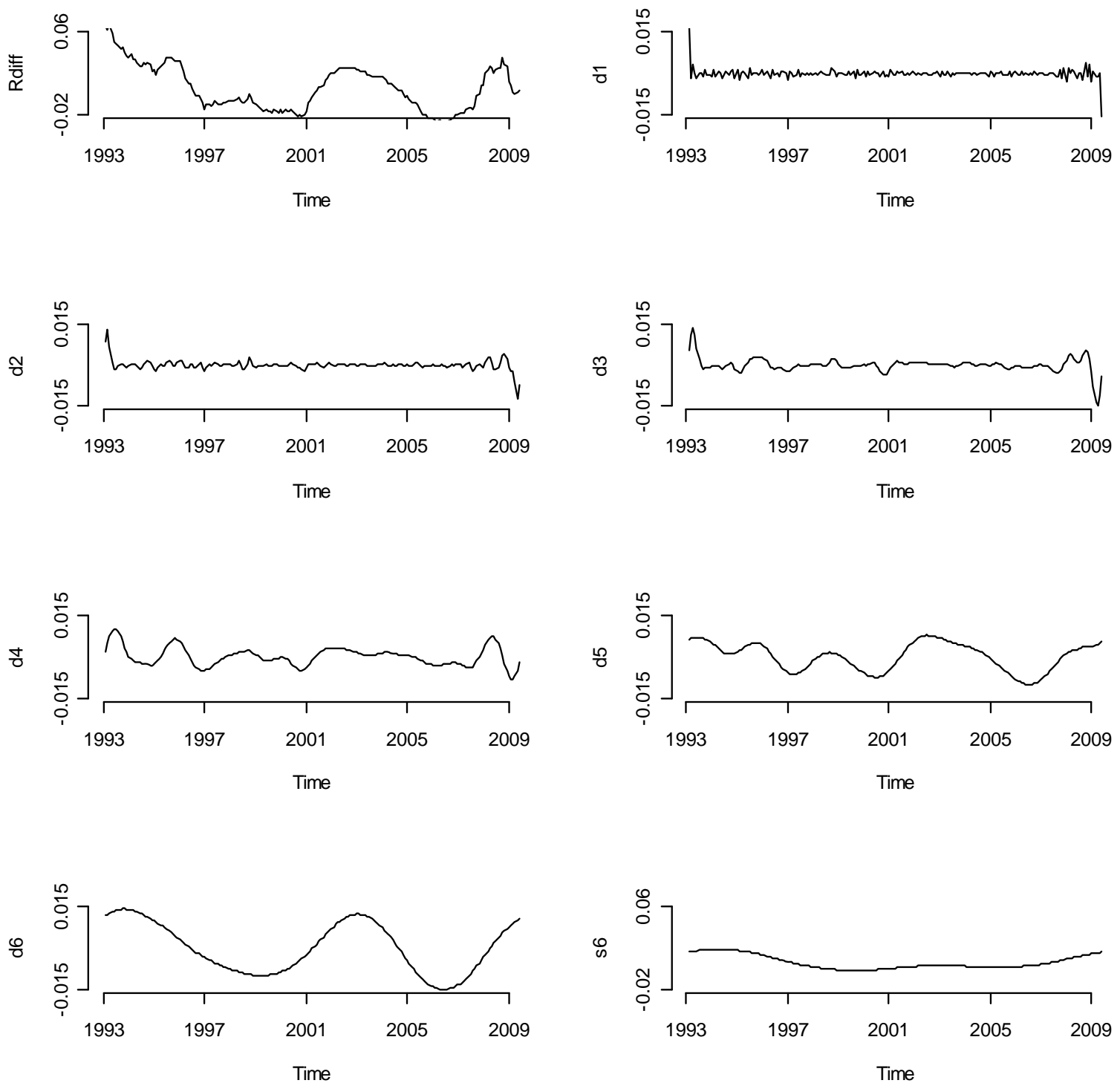

Figure 3. Time series plots of data for the monthly nominal interest differential between Sweden and the United States

\section{Empirical results}

In this section, the estimated coefficient of $\beta$, its corresponding standard error, and the $R^{2}$ of the associated regression are reported for the various scales and bilateral relationships for both monthly and quarterly data. Considering the limitations of the sample size, only the wavelet details at scale levels 1-5 are analyzed for the monthly data and at scale levels 1-4 for the quarterly data. ${ }^{21}$ Table 1 presents the results for the regressions using the monthly data. At the one-month wavelet scale, the relationship between the spot exchange rate and the nominal interest rate differential is estimated to be negative in four of the seven bilateral cases (once significantly so at the $1 \%$ level or lower, but otherwise with insignificance), implying that a higher nominal interest rate in Sweden relative to that in those foreign

\footnotetext{
${ }^{21}$ Detail series at level 6 were also available for the monthly data, but they are not used in the regression since the wavelet scale for $\mathrm{d} 6$ is 32 months, which means to complete one cycle, from peak to peak or trough to trough, requires at least twice that, at 64 months (5.33 years), which more than half of the sample period of one series, SEK-CHF, which has slightly less than ten years of data.
} 
countries results in an appreciation of the Swedish currency against the associated foreign currency. However, at this scale, the three other bilateral cases indicate the opposite-an estimated positive relationship between these variables (once significantly so at the $10 \%$ significance level). At both of the two-month and four-month wavelet scales, all of the bilateral cases are found to have a negative estimated relationship between the spot exchange rate and the nominal interest rate differential, with two bilateral cases at each of these scales indicating the estimated relationship is significant at the 5\% level or lower.

At the next wavelet scale of eight months, the number of negative estimated relationships between our variables of interest is reduced (five of seven, one significant at the $5 \%$ level) and at the largest wavelet scale of sixteen months there is a substantial reversal, with five positively estimated relationships between the spot exchange rate and the nominal interest rate differential, and three of these are significant at the 5\% level or lower (only one significantly negative estimated relationship is found).

Table 2 presents the regression results of the quarterly data series. In this case the first wavelet scale of one quarter has a scale which approximately corresponds to the monthlydata's $\mathrm{d} 2$ and $\mathrm{d} 3$ wavelet scales (two and four months respectively) in Table 1. By the same token, the quarterly data's second wavelet scale of two quarters approximately matches up with the monthly-data's $\mathrm{d} 3$ and $\mathrm{d} 4$ wavelet scales (four and eight months respectively) in Table 1. The wavelet scale dealt with in Table 2, eight quarters (2 years), has the longest time horizon in this analysis, requiring twice that, 16 quarters (4 years), to complete a cycle from peak to peak or trough to trough. 
Table 1. Regressions results in wavelet domain (monthly data)

\begin{tabular}{|c|c|c|c|c|c|c|}
\hline & & $\begin{array}{c}1 \text { month } \\
\text { (using } \\
\text { d1) }\end{array}$ & $\begin{array}{l}2 \text { months } \\
\text { (using } \\
\text { d2) }\end{array}$ & $\begin{array}{c}4 \text { months } \\
\text { (using } \\
\text { d3) }\end{array}$ & $\begin{array}{l}8 \text { months } \\
\text { (using d4) }\end{array}$ & $\begin{array}{l}16 \text { months } \\
\text { (using d5) }\end{array}$ \\
\hline \multirow[t]{2}{*}{ SEK per USD } & $\beta$ & $\begin{array}{l}-0.610548 \\
(0.977837)\end{array}$ & $\begin{array}{c}-1.319122 \\
(1.136317)\end{array}$ & $\begin{array}{c}-2.180114^{* * *} \\
(0.907696)\end{array}$ & $\begin{array}{c}-2.274403^{* *} \\
(1.035858)\end{array}$ & $\begin{array}{c}0.484843 \\
(0.937405)\end{array}$ \\
\hline & $R^{2}$ & 0.003106 & 0.013665 & 0.061588 & 0.146460 & 0.005390 \\
\hline \multirow[t]{2}{*}{ SEK per JPY } & $\beta$ & $\begin{array}{l}-1.860258 \\
(1.563332) \\
\end{array}$ & $\begin{array}{l}-2.857940 \\
(1.933806)\end{array}$ & $\begin{array}{c}-2.031024 \\
(2.630143) \\
\end{array}$ & $\begin{array}{c}-0.874484 \\
(1.660631) \\
\end{array}$ & $\begin{array}{c}2.570055^{* *} \\
(1.146333)\end{array}$ \\
\hline & $R^{2}$ & 0.024392 & 0.014306 & 0.068899 & 0.010814 & 0.056096 \\
\hline \multirow[t]{2}{*}{ SEK per EUR } & $\beta$ & $\begin{array}{l}-1.298757 \\
(1.498600)\end{array}$ & $\begin{array}{c}-1.797212^{* *} \\
(0.904149)\end{array}$ & $\begin{array}{l}-1.069843 \\
(1.059454)\end{array}$ & $\begin{array}{l}-3.619027 \\
(2.642949)\end{array}$ & $\begin{array}{c}3.742429 * * \\
(1.503269)\end{array}$ \\
\hline & $R^{2}$ & 0.028576 & 0.069845 & 0.058637 & 0.068828 & 0.117809 \\
\hline \multirow[t]{2}{*}{ SEK per GBP } & $\beta$ & $\begin{array}{c}0.739350 \\
(1.701446) \\
\end{array}$ & $\begin{array}{c}-2.181253^{* *} \\
(0.893200)\end{array}$ & $\begin{array}{c}-2.359305^{* *} \\
(1.157041) \\
\end{array}$ & $\begin{array}{l}-1.759639 \\
(0.829339) \\
\end{array}$ & $\begin{array}{l}-1.245387 \\
(0.770200)\end{array}$ \\
\hline & $R^{2}$ & 0.004018 & 0.039797 & 0.071901 & 0.072103 & 0.052977 \\
\hline \multirow[t]{2}{*}{ SEK per $\mathrm{CHF}$} & $\beta$ & $\begin{array}{c}-3.613164 * * * \\
(0.551475) \\
\end{array}$ & $\begin{array}{l}-1.737692 \\
(1.584535) \\
\end{array}$ & $\begin{array}{l}-3.084430 \\
(2.366053) \\
\end{array}$ & $\begin{array}{c}0.147851 \\
(2.309522) \\
\end{array}$ & $\begin{array}{c}0.877407 \\
(0.753099) \\
\end{array}$ \\
\hline & $R^{2}$ & 0.178382 & 0.028264 & 0.079371 & 0.000118 & 0.030648 \\
\hline \multirow[t]{2}{*}{ SEK per NOK } & $\beta$ & $\begin{array}{c}0.049291 \\
(0.453509) \\
\end{array}$ & $\begin{array}{c}-0.142409 \\
(0.652008)\end{array}$ & $\begin{array}{c}-0.196896 \\
(0.626426)\end{array}$ & $\begin{array}{c}-0.730885 \\
(0.576968)\end{array}$ & $\begin{array}{c}-1.592446 * * \\
(0.714298) \\
\end{array}$ \\
\hline & $R^{2}$ & 0.000112 & 0.000484 & 0.001636 & 0.034943 & 0.146776 \\
\hline \multirow[t]{2}{*}{ SEK per KRW } & $\beta$ & $\begin{array}{l}2.562177^{*} \\
(1.517248) \\
\end{array}$ & $\begin{array}{l}-0.228905 \\
(1.273994) \\
\end{array}$ & $\begin{array}{l}-0.588249 \\
(0.700550)\end{array}$ & $\begin{array}{c}0.504224 \\
(0.423084) \\
\end{array}$ & $\begin{array}{c}2.327020 * * * \\
(0.695812)\end{array}$ \\
\hline & $R^{2}$ & 0.060566 & 0.000586 & 0.009595 & 0.05823 & 0.192294 \\
\hline
\end{tabular}

Data used are monthly spot exchange rates and nominal interest rate differential. Spot rates are prices of a unit foreign currency in units of Swedish Kronor. The only exception is the Swedish Krona to Korean won exchange rate, which is in terms of Kronor per 100 won. The wavelet coefficients are calculated using Haar filter. Standard errors are in parenthesis under the coefficient estimates. $* * *, * *$ and $*$ indicate the significance level at $1 \%, 5 \%$, and $10 \%$ level, respectively.

In Table 2, we see a repetition of the negative relationship that is so dominant at the two- and four-month wavelet scale from Table 1 with the one-quarter wavelet scale; all of the bilateral cases except one indicate an estimated negative relationship between the exchange rate and the nominal interest rate differential at this lowest scale with the quarterly data, with three of these estimates significant at the $1 \%$ level. As we increase the wavelet scale to two quarters, to four quarters, and finally to eight quarters, we see the number of bilateral cases with negative point estimates on the relationship between the exchange rate and the nominal interest rate differential decreasing respectively to five, three and two. The largest wavelet scale considered, eight quarters, has three of its five positive estimates on this relationship significant at the $5 \%$ level or lower.

Figure 2 illustrates the Table 1 point estimates for $\beta$ using the monthly data, and Figure 3 does the same for the quarterly-data estimates from Table 2. What these figures portray, especially Figure 3, is the general upward trend in the $\beta$ estimates after the four-month or one-quarter wavelet scale. This is consistent with the results from flexible-price models gaining more influence with a greater time scale considered. 
Table 2. Regression in wavelet domain (quarterly data)

\begin{tabular}{|c|c|c|c|c|c|}
\hline & & $\begin{array}{c}1 \text { month } \\
\text { (using d } 1 \text { ) }\end{array}$ & $\begin{array}{l}2 \text { months } \\
\text { (using d2) }\end{array}$ & $\begin{array}{c}4 \text { months } \\
\text { (using d3) }\end{array}$ & $\begin{array}{l}8 \text { months } \\
\text { (using d4) }\end{array}$ \\
\hline \multirow[t]{2}{*}{ SEK per USD } & $\beta$ & $\begin{array}{c}-1.047582 \\
(0.669475)\end{array}$ & $\begin{array}{l}-2.833687 \\
(1.711768)\end{array}$ & $\begin{array}{c}0.047425 \\
(1.342256)\end{array}$ & $\begin{array}{c}1.375533 \\
(0.854749)\end{array}$ \\
\hline & $R^{2}$ & 0.018774 & 0.137715 & 0.000047 & 0.071157 \\
\hline \multirow[t]{2}{*}{ SEK per JPY } & $\beta$ & $\begin{array}{l}-3.180927 \\
(2.692139)\end{array}$ & $\begin{array}{c}0.444922 \\
(1.920093)\end{array}$ & $\begin{array}{c}1.393765 \\
(1.174635)\end{array}$ & $\begin{array}{c}6.720737^{* * *} \\
(2.002273)\end{array}$ \\
\hline & $\mathrm{R}^{2}$ & 0.059900 & 0.001674 & 0.022780 & 0.296078 \\
\hline \multirow[t]{2}{*}{ SEK per EUR } & $\beta$ & $\begin{array}{c}- \\
3.165806 * * * \\
(0.891253)\end{array}$ & $\begin{array}{l}-1.933111 \\
(1.743933)\end{array}$ & $\begin{array}{c}0.422466 \\
(1.770909)\end{array}$ & $\begin{array}{l}3.625346^{* *} \\
(1.547813)\end{array}$ \\
\hline & $R^{2}$ & $(0.317871)$ & 0.043595 & 0.000986 & 0.297089 \\
\hline \multirow[t]{2}{*}{ SEK per GBP } & $\beta$ & $\begin{array}{c}-0.166143 * * * \\
(0.035526)\end{array}$ & $\begin{array}{c}-0.282020^{* * *} \\
(0.034941)\end{array}$ & $\begin{array}{l}-0.098779 \\
(0.064212)\end{array}$ & $\begin{array}{c}-0.023498 \\
(0.050410)\end{array}$ \\
\hline & $R^{2}$ & 0.248301 & 0.316669 & 0.055849 & 0.006638 \\
\hline \multirow[t]{2}{*}{ SEK per CHF } & $\beta$ & $\begin{array}{c}- \\
5.717912 * * * \\
(1.713635)\end{array}$ & $\begin{array}{c}-0.595841 \\
(1.595841)\end{array}$ & $\begin{array}{c}-0.885062 \\
(1.224635)\end{array}$ & $\begin{array}{c}0.172484 \\
(0.654368)\end{array}$ \\
\hline & $R^{2}$ & 0.279642 & 0.002674 & 0.032124 & 0.003666 \\
\hline \multirow[t]{2}{*}{ SEK per NOK } & $\beta$ & $\begin{array}{c}0.203039 \\
(0.810219)\end{array}$ & $\begin{array}{l}-0.205568 \\
(0.751350)\end{array}$ & $\begin{array}{l}-0.826537 \\
(0.895334)\end{array}$ & $\begin{array}{l}-0.675303 \\
(0.601240)\end{array}$ \\
\hline & $R^{2}$ & 0.001158 & 0.002244 & 0.039810 & 0.062950 \\
\hline \multirow[t]{2}{*}{ SEK per KRW } & $\beta$ & $\begin{array}{l}-0.009474 \\
(2.833141)\end{array}$ & $\begin{array}{c}0.988952 \\
(0.857730)\end{array}$ & $\begin{array}{c}0.605531 \\
(0.907765)\end{array}$ & $\begin{array}{c}3.784448^{* * *} \\
(1.093194)\end{array}$ \\
\hline & $R^{2}$ & 0.000001 & 0.024983 & 0.027493 & 0.253784 \\
\hline
\end{tabular}

Data used are quarterly spot exchange rates and nominal interest rate differential. Spot rates are prices of a unit foreign currency in units of Swedish Kronor. The only exception is the Swedish Krona to Korean won exchange rate, which is in terms of Kronor per 100 won. The wavelet coefficients are calculated using Haar filter. Standard errors are in parenthesis under the coefficient estimates. $* * *, * *$ and $*$ indicate the significance level at $1 \%, 5 \%$, and $10 \%$ level, respectively.

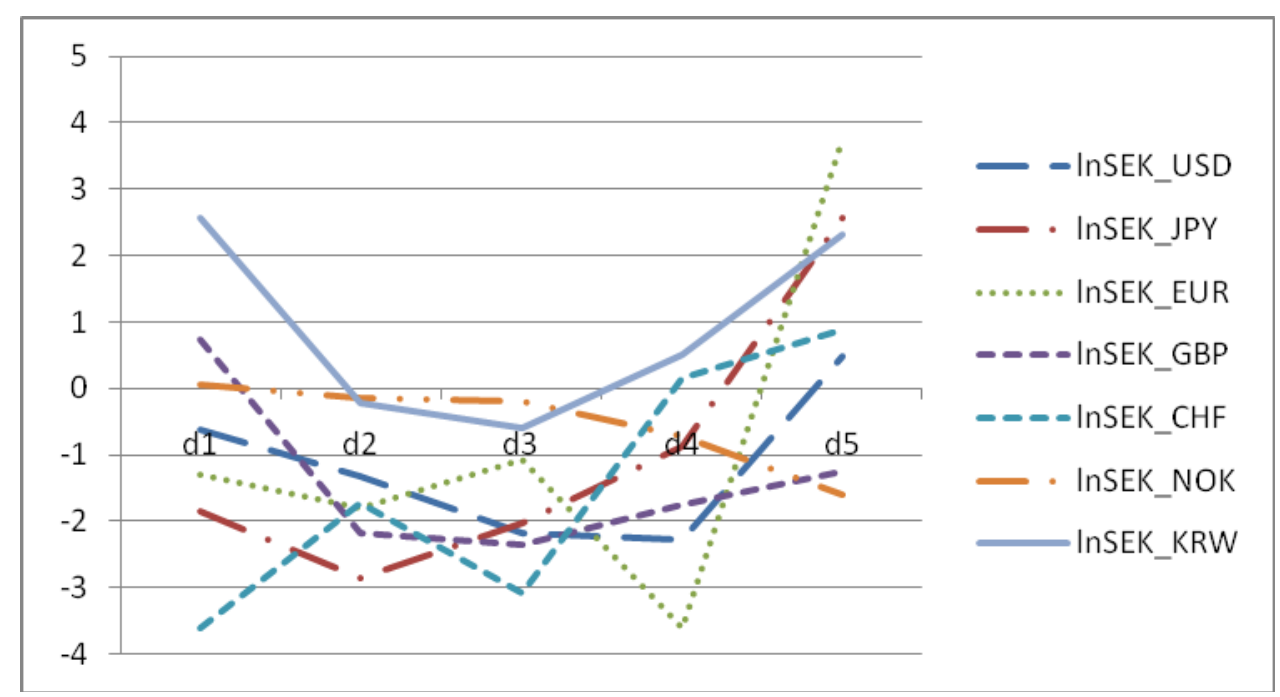

Figure 2. Graphical representation of the $\beta$ estimates from the regressions using monthly data 


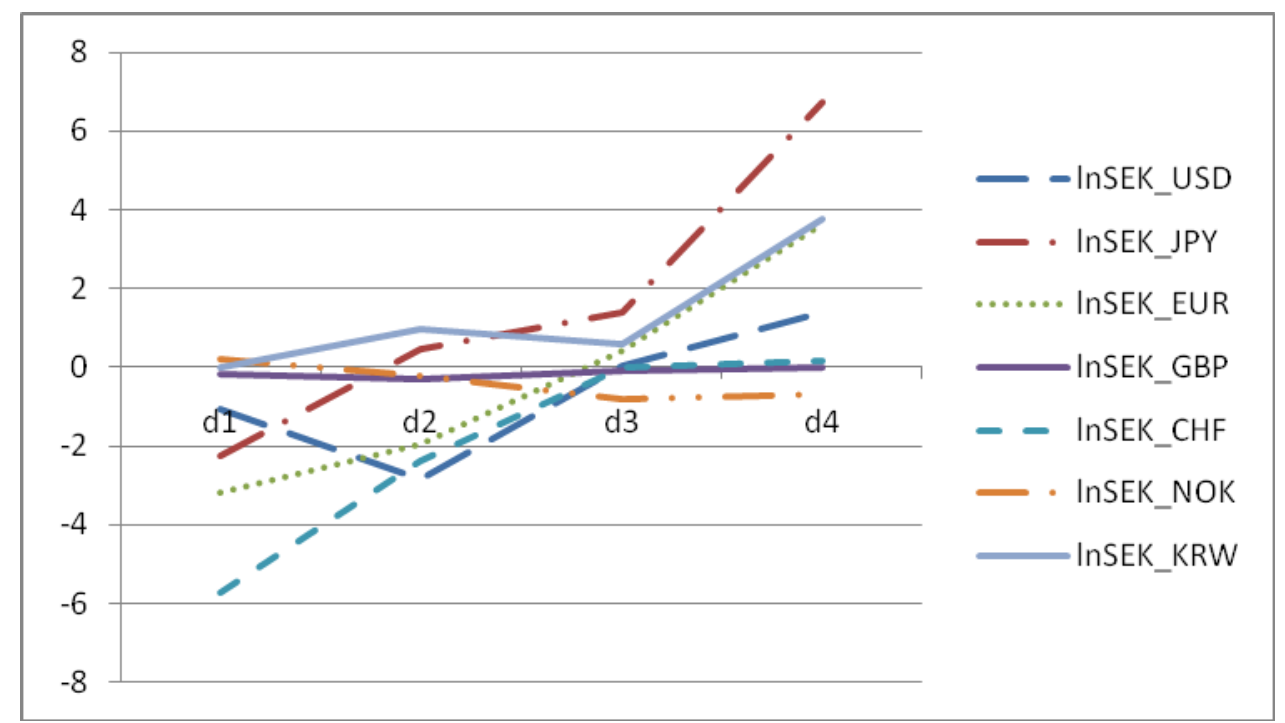

Figure 3. Graphical representation of the $\beta$ estimates from the regressions using quarterly data

In the first two sections, we discussed the conflicting relationship between the spot exchange rate and the interest rate differential depending on different assumptions about price flexibility. We can see from our results that there appears to exist a negative relationship between the spot exchange rate and nominal interest rate differential at the shorter-time horizon with wavelet scales less than a year, especially around three to four months. That relationship is reversed in sign with the longer-time horizons, those with wavelet scales over a year. This changing of the estimated signs on the relationship is consistent with sticky-price models dominating in the short run and flexible-price monetary models dominating in the long run. Furthermore, this may be considered similar to findings by others when estimating how the change in the log exchange rate is linearly related to the interest rate differential when using short-maturity bond data and when using long-term bond data; in those studies a negative relationship often appears when dealing with the shorter periods whereas a positive relationship often appears when dealing with longer periods (see the discussion in section 3 above dealing with Chinn and Meridith, 2004, 2005).

It is also notable that with the monthly data that the strength of the evidence for a negative relationship between the spot exchange rate and nominal interest rate differential is weakened as the wavelet scale is reduced below four months to two months and then to one month (the point estimates for $\beta$ are in most cases increasing as we consider these successively lower scales). This possibly has to do with the reduced importance of fundamental economic variables in affecting exchange rate and interest movements at the lowest scales, at which point traders in the foreign exchange and bond markets are more likely to be influenced by short-term market trends.

\section{Conclusion}

The main innovation of this paper is the introduction of a new methodology to study the relationship between spot exchange rate and nominal interest rate differential. This new methodology is based on decomposing time-series at different scales and allows us to study the series on a scale-by-scale basis. Regression analysis in the wavelet domain was adopted since the wavelet transform has advantages in dealing with non-stationary economic timeseries and in considering time-varying relationships. 
The results of the regression analyses in the wavelet domain show that the relationship between the variables of interest tends to be negative at the shorter time horizons, at wavelet scales of a half year or less, while a positive relationship tends to be observed in the longer horizons over a year. The results when using the two different data frequencies - monthly and quarterly - are consistent with each other in this finding.

Exploring the relationship between the exchange rate and the interest rate differential involves dealing with the issue that prices tend to move more slowly over shorter time scales, and that is why there have been broadly two theoretical approaches in explaining the relationship. The key findings of this paper are consistent with the theoretical underpinnings of both sticky-price and flexible price exchange-rate determination models following an asset approach; the former predict a negative relationship between the exchange rate and the interest rate differential in the short-run with price stickiness, while the latter claim a positive relationship in the long-run with the flexible movement of the price levels.

Overall, the time-scale decomposition of the exchange rates and the interest rate differentials has provided insights to the testing of the relationship between these variables at different time scales. Puzzles and failures of previous empirical findings on relationships which have a strong time scale element have a possibility of being resolved and further explained by wavelet analysis.

\section{References}

Asea, Patrick K. and Mendoza, Enrique G. (1994) Do Long-run Productivity Differential Explain Long-run Exchange Rate? Review of International Economics 2(3), pp. 244-267.

Balassa, Bela (1964) The Purchasing Power Parity Doctrine: A Reappraisal. Journal of Political Economy, 72(6), pp. 584-596.

Betts, Caroline and Devereux, Michael B. (2000) Exchange rate dynamics in a model of pricing-to-market, Journal of International Economics, 52(1), pp. 215-244.

Berkowits, Jeremy and Giorgianni, Lorenzo (2001) Long-Horizon Exchange Rate Predictability? Review of Economics and Statistics, 83(1), pp. 81-91.

Bilson, John F.O. (1978) The Monetary Approach to the Exchange Rate-Some Empirical Evidence. International Monetary Fund Staff Papers, 25(1), pp. 48-75.

Blanchard, Oliver J.; Giavazzi, Francesco; and Sa, Filipa (2005) The U.S. Current Account and the Dollar. NBER Working Paper no. 11137.

Branson, William H. and Henderson, Dale W. (1985) The Specification and Influence of Asset

Markets. In Handbook of International Economics, Vol. 2, Ronald W. Jones and Peter B. Kenen, eds., pp.749-805. Amsterdam: Elsevier.

Cheung, Yin-Wong; Chinn, Menzie D. and Pascual, Antonio Garcia. (2005) Empirical Exchange Rate Models of the Nineties: Are Any Fit To Survive? Journal of International Money and Finance, 24(7), pp. 1150-1175. 
Chinn, Menzie D. (1997) Paper Pushers or Paper Money? Empirical Assessment of Fiscal and Monetary Models of Exchange Rate Determination. Journal of Policy Modelling, 19(1), pp. 51-78.

Chinn, Menzie D. and Meese, Richard A. (1995) Banking on Currency Forecasts: How Predictable Is Change in Money? Journal of International Economics, 38(1/2), pp. 161-78.

Chinn, Menzie D. and Meredith, Guy (2004) Monetary Policy and Long Horizon Uncovered Interest Parity. IMF Staff Papers. 51(3) pp. 409-430.

Chinn, Menzie D. and Meredith, Guy (2005) Testing Uncovered Interest Parity at Short and long Horizons during the Post-Bretton Woods Era. NBER Working Paper No. 1107 (January).

Clements, K., Frenkel, Jeffrey (1980) Exchange rates, money and relative prices: the dollarpound in the 1920s. Journal of International Economics 10, pp. 249-262.

Copeland, Laurence (2008) Exchange Rates and International Finance. Edinburgh, England: Pearson Education Ltd.

Davidson, Russell and MacKinnon, James G. (1993) Estimation and Inference in Econometrics. Oxford: Oxford University Press.

DeGregorio, Jose, and Wolf, Holger. (1994) Terms of trade, productivity, and the real exchange rate. NBER Working Paper No. 4807.

Dornbusch, Rudiger. (1976) Expectations and Exchange Rate Dynamics. Journal of Political Economy, 84(6), pp. 1161-76.

Edwards, Sebastian (2005) Is the U.S. Current Account Sustainable? If Not, How Costly is Adjustment Likely to Be? Brookings Papers on Economic Activity (1), pp. 211-271.

Engels, Charles and West, Kenneth D. (2005) Exchange Rates and Fundamentals. Journal of Political Economy, 113(3). pp. 485-517.

Faust, Jon; Rogers, John H. and Wright, Jonathan H. (2003) Exchange Rate Forecasting: The Errors We've Really Made. Journal of International Economics, 60(1), pp. 35-59.

Fisher, Irving (1930) The Theory of Interest. Macmillan: New York.

Flemming, J. Marcus (1962) Domestic Financial policies Under Fixed and Floating Exchange Rates, International Monetary Staff Papers, 9(3), pp. 369-79.

Flood, Robert P., and Taylor, Mark P. (1996) Exchange Rate Economics: What's Wrong with the Conventional Macro Approach? In The Microstructure of Foreign Exchange Markets, Jeffrey A Frankel, Giampaolo Galli, and Alberto Giovannini eds., pp. 261-302. Chicago: University of Chicago Press. 
Froot, Kenneth A., and Thaler, Richard H. (1990) Anomalies: Foreign Exchange. Journal of Economic Perspectives. 4(3) pp. 179-192.

Frankel, Jeffrey (1979) On the Mark: A Theory of Floating Exchange Rates Based on Real Interest Differential. The American Economic Review, 69(4), pp. 610-622.

Frenkel, Jacob A. (1976) A Monetary Approach to the Exchange Rate: Doctrinal Aspects and Empirical Evidence. Scandinavian Journal of Economics, 78(2), pp. 200-24.

Grossman, A. and Morlet, J. (1984) Decomposition of Hardy Functions into Square Integrable Wavelets of Constant Shape. SIAM Journal of Mathematical Analysis, 15, 723736.

Haar, Alfred (1910) Zur Theorie der orthogonalen Funktionensysteme. Mathematische Annalen, 69(3), 331-371. In German.

Hooper, Peter and Morton, John E. (1982) Fluctuations in the Dollar: A Model of Nominal and Real Exchange Rate Determination. Journal of International Money and Finance, 1(1), pp. 39-56.

Mallat, S. (1989) A Theory for Multiresolution signal decomposition: The Wavelet representation. IEEE Transactions on Pattern Analysis and Machine Intelligence, 11(7), pp. 674-693.

Lane, Philip R. (2001) The New Open Economy Macroeconomics: a Survey. Journal of International Economics, 54(2) pp. 235-266.

Mark, Nelson C. (1995) Exchange Rates and Fundamentals: Evidence on Long-Horizon Predictability. American Economic Review, 85(1) pp. 201-18.

Mark, Nelson C. and Sul, Donggyu (2001) Nominal Exchange Rates and Monetary Fundamentals: Evidence from a Small Post-Bretton Woods Panel. Journal of International Economics, 53(1), pp. 29-52.

Meese, Richard A. and Rogoff, Kenneth (1983a) Empirical Exchange Rate Models of the Seventies: Do They Fit Out of Sample?, Journal of International Economics, February, 14(1/2), pp. 3-24.

Meese, Richard A. and Rogoff, Kenneth (1983b) The Out-of-Sample Failure of Empirical Exchange Rate Models: Sampling Error or Misspecification? In Exchange Rates and International Macroeconomics, ed. Jacob Frenkel, pp. 67-105 . Chicago: NBER and University of Chicago Press,.

Mundell, Robert A. (1962) The Appropriate Use of Monetary and Fiscal Policy for Internal and External Stability, International Monetary Funds Staff Papers, 9(1), pp.70-79

Mundell, Robert A. (1963) Capital Mobility and Stabilization Policy under Fixed and Floating Exchange Rates, Canadian Journal of Economic and Political Science, 29(4), pp.475-85. 
Neely, Christopher J. and Sarno, Lucio (2002) How Well Do Monetary Fundamentals Forecast Exchange Rates? Federal Reserve Bank of St. Louise Review, 84(Sep./Oct.), pp. 5174.

Obsfeld, Maurice (1993) Model Trending Real Exchange Rates. Center for International and Development Economics Working Paper C93-011, University of California at Berkeley.

Percival, Donald B. and Walden, Andrew T (2006) Wavelet Methods for Time Series Analysis. Cambridge: Cambridge University Press.

Percival, Donald B., Sardy, S. and Davison A. C. (2000) Wavestrapping time series: Adaptive wavelet-based bootstrapping, In Nonlinear and Nonstationary Signal Processing, Fitzgerald, W. J., Smith, R. L., Walden, A. T., and Young, P. C. eds, pp. 442-471, Cambridge: Cambridge University Press.

Ramsey, James B. and Lampart, Camille (1998) Decomposition of Economic Relationships by Timescale Using Wavelets. Macroeconomic Dynamics, 2(1), pp.49-71.

Rapach, David E. and Wohar, Mark E. (2002) Testing the Monetary Model of Exchange Rate Determination: new evidence from a century of data. Journal of International Economics, 58(2), pp. 359-385.

Samuelson, Paul (1964) Theoretical Notes on Trade Problems, Review of Economics and Statistics, 46, pp. 145-154.

Samo and Taylor (2004) The Economics of Exchange Rates. Cambridge: Cambridge University Press.

Schleicher, Christoph (2002) An Introduction to Wavelets for Economists. Working Paper 2002-3, Bank of Canada.

Strömberg, Jan-Olov (2006) A Modified Franklin System and Higher Order Spline Systems on $\mathrm{R}^{\mathrm{n}}$ as Unconditional Bases for Hardy Spaces, In Fundamental Paper in Wavelet Theory, Heil, C., and Walnut, D.F. eds, pp. 197-215. Princeton: Princeton University Press. 